九州大学学術情報リポジトリ

Kyushu University Institutional Repository

On Database File ELKUType Based on the Type Collection Preserved in the Entomological Laboratory, Kyushu University

Tadauchi, 0samu

Kamitani, Satoshi

Inoue, Hitoshi

Dawut, Ahmatjan

https://doi.org/10.5109/2660

出版情報: ESAKIA. 42，pp.41-46，2002-03-31. Entomological Laboratory，Faculty of Agriculture， Kyushu University

バージョン :

権利関係 : 


\title{
On Database File ELKUType Based on the Type Collection Preserved in the Entomological Laboratory, Kyushu University 1), 2)
}

\author{
Osamu TADAUCHI, Sàtoshi KAMITANI \\ Entomological Laboratory, Faculty of Agriculture, Kyushu University, \\ Fukuoka, 812-8581 Japan \\ Hitoshi $\mathbb{N O U E}$ \\ Computing and Communications Center, Kyushu University, \\ Fukuoka, 812-8581 Japan \\ and
}

\begin{abstract}
Ahmatjan DAWUT
Entomological Laboratory, Graduate School of Bioresource and Bioenvironmental Science, Kyushu University, Fukuoka, 812-8581 Japan
\end{abstract}

\begin{abstract}
A database file, ELKUType, based on the type collection preserved in the Entomological laboratory, Kyushu University, Fukuoka, Japan was constructed as one of the files in the KONCHU database and is available to the public via the Internet. Each record is composed of 19 items, and consists of scientific name, Japanese name, current species name, order, family, author, year, source of the original description including bibliographic data, type designation with sex, type locality, country, preservation form, existence of paratypes and an image of the type specimen. A home page of the ELKUType database is presented. It is administered by a SIGMA management system. A user can access the database file by visiting the following URL: http://konchudb.agr.agr. kyushu-u.ac.jp/ elkutype/.

Key words: bioinformatics, entomology database, KONCHU, type specimens, ELKUType, SIGMA, Kyushu University.
\end{abstract}

1) Contribution from the Entomological Laboratory, Faculty of Agriculture, Kyushu University, Fukuoka (Ser. 5, No. 71).

2) This work was partly supported by a Grant-in-Aid for Scientific Research (B)(2) from the Ministry of Education, Science, Sports and Culture, Japan and Japan Society for the Promotion of Science (Head Investigator: O. Tadauchi, No. 09490028). 
The Entomological Laboratory of Kyushu Univertsity was founded in 1921 and was one of the five oldest laboratories in the Faculty of Agriculture, Kyushu Imperial University. Professor Teiso Esaki, who began his post as associate professor in 1923, and his collaborators founded the Kyushu University Insect Collection (Hirashima, 1988). The Micronesia Collection in Kyushu University is one of his most notable collections. Since then, many taxonomists and systematists have been educated under Prof. Esaki and succeeding professors, all of whom contributed to the field of taxonomy and systematics in entomology. They described many new species in their works and deposited the holotypes in the Entomological Laboratory, Kyushu University.

Professor Yoshihiro Hirashima prepared type specimen cards for the type specimens and himself recorded data in his active service contributing to the No. 2 series of the type collection (Tadauchi \& Nomura, 2000). Associate Professor Koji Yano and Associate Professor Michitaka Chujo prepared and archived documents for the type specimens in the periods representing the appointments of Prof. Esaki and Prof. Yasumatsu.

Individual researchers can spend a significant portion of their time and budget visiting museums in an effort to examine a handful of type specimens of species inadequately described or illustrated. Alternatively, types can be shipped, risking specimen loss or damage (MCZ, Harvard Univ., 1999). A database file including specimen images will play an important role in systematics in the near future. Recently, various museums and university museums around the world have developed type specimen databases, some of them including digital images on insects. These databases can be publicly accessed online, e.g. , Harvard Univ. (MCZ, Primary Types Database) and Smithsonian Inst. (NMNH, Type Specimen Database).

We constructed the ELKUType database based on the type collection preserved in the Entomological Laboratory, Kyushu University. It can be accessed publicly via the Internet. Each record is composed of 19 items with the following tags:
1. (NO) Registration number
2. (RES) Registration date
3. $(\mathrm{TAX})$ Scientific name
4. (JTAX) Japanese name
5. (CN) Current species name (if available)
6. (OR) Order
7. (FAM) Family
8. (AU) Author
9. (Y) Year described
10. (T) Title of the original description
11. (J) Journal
12. (VNP) Volume, number, page
13. (DES) Type designation with sex 


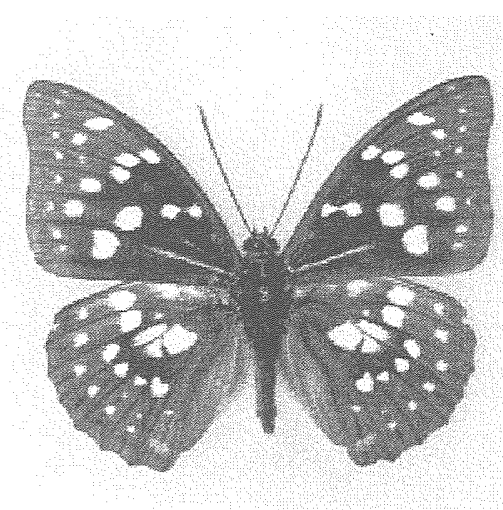

\section{Welcome to Entomology Database KONCHU!}

\section{Species Information Database on Japanese, East Asian and Pacific Insects, Spiders and Mites}

Entomological Laboratory, Kyushu University

Japanese page is here

An entomology database KONCHU is a general database name including various files treating species information on Japanese, East Asian and Pacific insects (including spiders and mites) as follows.

- Entomology reference database based on main Japanese entomological and zoological journals - KONCHUR

- Image database on useful Japanese insects

- HANABACHI (bees)

- KOBACHI (parasitic wasps) (coming soon)

- MOKUROKU database based on "A Check List of Japanese Insects"

- MOKUROKU

- Dictionary of Japanese insect names

- DII (scientific and Japanese names)

- Type specimen database based on the Collection of Entomological Laboratory, Kyushu University

- ELKUType (coming soon)

The KONCHU is managed by a text database management system SIGMA.

KONCHU is supported by a Grant-in-Aid for Publication of Scientific Research Result and a Grant-in-Aid for Scientific Research (B) from the Ministry of Education, Science, Sports and Culture, Japan and Japan Society for the Promotion of Science.

The use of data in this database is free of charge if the objective is academic study or educalional purposes.

\section{Inquiries and Comments}

Inquiries and Comments about KONCHU Should be the Following E-mail Address.

Entomology database KONCHU (Osamu Tadauchi)

Entomological Laboratory,

Faculty of Agriculture,

Kyushu University

Fukuoka, 812-8581

Japan

Phone: +81-92-642-2838 FAX: +81-92-642-2839

E-mail: tadauchi@agekushu-u-acip

Fig. 1. A top page of the KONCHU database including various files relating to species information on Japanese, East Asian and Pacific insects.The ELKUType file is included as one of the files. 
14. (LOC) Type locality and other data in the type label

15. (CO) Country

16. (PRS) Preservation form (dried, in alcohol, prepared, etc.)

17. (PTYPE) Paratypes

18. (NOTE) Note

19. (IMAG) Image of the type specimen

An example of a record is as follows:

\#

(NO) 2019

(RES) $\quad 1973.8 .7$

(TAX) Megachile (Megachile) yasumatsui Hirashima

(JTAX) ヤスマツハキリバチ

(OR) Hymenoptera ハチ目

(FAM) Megachilidae ハキリバチ科

(CN)

(AU) HIRASHIMA, Yoshihiro

(Y) 1973

(T) Annotated check list of the Japanese species of the genus Megachile sensu lato

(Hymenoptera, Megachilidae), with description of a new species

(J) Kontyu

(VNP) $\quad 42(2): 176-178$ (pp. 174-180)

(DES) holotype, female

(LOC) Koshozan, Fukuoka Pref., Kyushu, Japan, 12. viii. 1934, K. Yasumatsu leg.

(CO) Japan

(PRS) dried

(PTYPE) paratypes: 11 females \& 4 males

(NOTE) ELKU Contr. No.: Ser. 3, No. 8

(IMAG) $\quad$ Megachile yasumatsui

The database is written mainly in English with Japanese and is administered by a SIGMA text database management system working at a workstation in the Entomological Laboratory at Kyushu University.

A user can access to the ELKUType file by visiting the following URL: http:// konchudb.agr. agr.kyushu-u.ac.jp/elkutype/. 


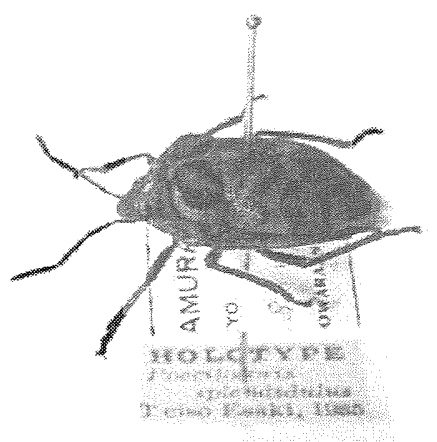

\section{Welcome to Database $\mathbb{E L} \mathbb{K} U T$ Tye Based on the Type Specimen Collection Preserved in the Entomological Laboratory, Kyushu University!}

Jamurese parge is lzere

A database filc ELKC Yype treais information of type specimens based on the collection preserved in the Entomological Laboratory,

Kyusbu University, Fukuoka, Japar. The types are specimens used in the original description for constracting a new taxon such as a new species. One of them is called the holotype as the representative individual of the new species and the other specimens designated are called paratype(s). The ELKUType is a database mainly based on the holotypes. Each record is composed of 19 items, such as scientific name, paratype(s). The ELKUType is a database mainly based on the holotypes. Each record is composed of 19 items, such as scientific name, existence of paratypes, image, ctc.

The ELKUTYpe is managed by a text database mamagement system SIGMA.

The EL_KUType is partly supported by a Grant-in-Aid for Scientific Research(B)(2) from the Ministry of Education, Science, Sports and Culture, Japan.

The use of data in this database is free of charge if the objective is academic study or educational purposes.

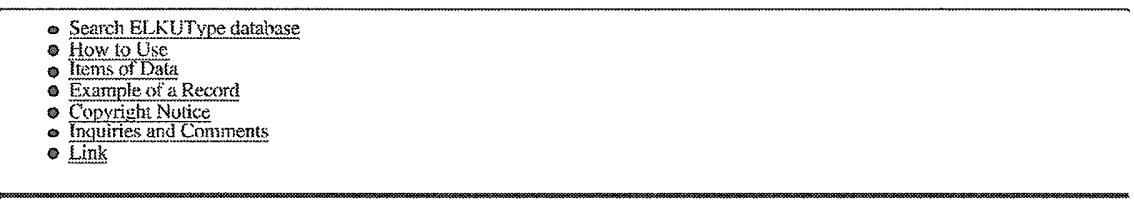

\section{Items of Data}

Data and Tags are the Following 19 itcms.
1. $(\mathrm{NO})$ Reyistration number
2. (RES) Registration date
3. (TAX) Scientific name
4. (JTAX) Japanese name
5. (CN) Current species name (if available)
6. (OR) Orcier
7. (FAM) Family
8. (AU) Author
9. (Y) Year described
10. (T) Trule of the original description
11. (J) Joumal
12. (YNP) Volume, no, page
13. (DES) Type designation with sex
14. (LOC) Type locality and other data in the type label
15. (CO) Country
16. (PRS) Preservation forn (dried, in alcohol, prepared, elc)
17. (PTYPE) Paratype
18. (NOTE) Note
19. (IMAG) Image of the lype specimen

Fig. 2. The home page of the ELKUType database based on the type collection preserved in the Entomological Laboratory, Kyushu University, Fukuoka, Japan (in English version). 
The home page of the KONCHU and ELKUType databases are presented in Figs. 1 and 2. The operation of the SIGMA system is explained in Arikawa et al. $(1987,1988)$.

\section{Acknowledgments}

We are grateful to Prof. Emeritus Y. Hirashimà of Kyushu University, Prof. Emeritus K. Yano of Yamaguchi University, former Associate Prof. M. T. Chujo of Kyushu University and Prof. Emeritus K. Morimoto of Kyushu University for their preparation of type specimen cards or primary sources which were useful to our present work. We are also indebted to Prof. J. Yukawa of Kyushu University and Prof. S. Arikawa, Head of the SIGMA Project Group at Kyushu University for their help and support.

\section{References}

Arikawa, S. et al., 1987. A text database management system SIGMA, Version 2. Koho, Computer Center Kyushu Univ., 20: 517-581. (In Japanese.)

Arikawa, S. et al., 1988. SIGMA: A text database management system. RIFIS Techn. Rep., Res. Inst. Fundam. Inform. Sci., Kyushu Univ., CS-3: 1-16.

Hirashima, Y., 1988. Teiso Esaki (1899-1957). Esakia, (26): 1-4.

MCZ, Harvard University, 1999. Home page. http://mcz-28168.oeb.harvard.edu/mcztypedb.htm/

Tadauchi, O. \& S. Nomura, 2000. [6-9 Registration]. pp. 632-636, In Baba, K. \& Y. Hirashima (eds.), Entomosyllegology, New ed. Kyushu University Press, Fukuoka. (In Japanese.) 